\title{
MEAN-LAYER WIND CHARTS IN TROPICAL ANALYSIS
}

\author{
JOSÉ A. COLÓN AND EDWARD J. ZIPSER 1 \\ National Hurricane Research Project, U.S. Weather Bureau, Miami, Fla. \\ [(Manuscript received May 4, 1962; revised August 1, 1962)]
}

\section{ABSTRACT}

\begin{abstract}
A discussion of the usefulness of mean-layer winds-defined in terms of the net horizontal displacement of the balloon during the time interval that it ascends through specified layers-in tropical analysis and forecasting is presented. Selected wind soundings in the trade wind regime are used to illustrate the greater representativeness and reliability of the mean winds. Some evidence is presented to support the contention that the wind report in the center of a layer cannot always be trusted to give a reliable picture of the layer as a whole. Other arguments are presented in support of the mean-layer winds for analysis and forecasting purposes, and for computations of derived properties of the field of motion. Some remarks on the analysis of these charts, based on the experience obtained at the National II urricane Research Project, are included.
\end{abstract}

\section{INTRODUCTION}

In any evaluation of the state of the atmosphere (such as a forecaster might make), all information is supposedly useful. In considering the wind field, knowledge of the vertical wind sounding at each station and of the field distribution of the wind velocity at ench level reported would be desirable. Efforts have incessantly been made to devise techniques which would allow assimilation of all the potentially useful information by an individual in a reasonable amount of time. Generally, some small numbers of charts are selected for consideration in which, hopefully, most of the important information is contained. In most analysis and forecasting programs, the surface chart, complemented by a series of upper-air charts, is utilized. The surface chart has serious disadvantages in defining the wind field in the Tropies, mainly because of unrepresentativeness of surface reports from land stations. Lilly and LaSeur [3] have shown that at several stations in the Caribbean area important local effects on the winds exist not only at the surface but to altitudes of at least 2,000-4,000 ft. Thus analysis at levels high enough to be above most of the local influences should be more fruitful. It is proposed here that a mean wind defined so that it is representative of the meaningful layers of interest permits the analysis in only one chart of a significant portion of the information necessary to describe the properties of the layer as a whole.

Since 1958 , and at the initiative of the National Hurricane Research Project (NHRP), most rawinsonde stations in the West Indies Network have computed and transmitted mean-layer winds. ${ }^{2}$ At present these winds are

\footnotetext{
1 Present address: Florida State University, Tallahassee, Fla.

2 The mean-layer winds are sometimes referred to as $\mathrm{CZ}$ winds, after the heading identifier under which they are transmitted through the teletypewriter network.
}

computed for the layers $3,000-10,000 \mathrm{ft}$.; $16,000-23,000$ $\mathrm{ft}$; and $37,000-42,000 \mathrm{ft}$. These intervals were selected to define the flow at the three layers of interest in the Caribbean area: the low-level regime-the trades; the upper-level wind regime $(37,000-42,000 \mathrm{ft}$.), characterized in summer by a complex cellular structure of cyclones and anticyclones and in winter by a fairly persistent and strong westerly current; and the middle layer transition zone, centered near the $500-\mathrm{mb}$. surface, often characterized by weak winds but sometimes containing features of the regimes above and below it. These mean winds are computed at the stations during the evaluation of the sounding and are obtained from the net displacement of the balloon during the time interval that it ascends through the specified layers.

During the 1960 and 1961 hurricane seasons a daily analysis of the low-level and upper-level mean-layer wind charts was carried out as part of the analysis program at the National Hurricane Center in Miami. The authors participated actively in the analyses and interpretation of these charts. It seems advisable at this time to bring these charts to the attention of others and to discuss some of their advantages and disadvantages.

\section{SOME REMARKS ON WIND ANALYSIS IN THE TROPICS}

One of the most important factors in arriving at a particular analysis is the amount of confidence that the analyst can place in a given report. Involved in this are questions of accuracy, precision, and what may be referred to as "representativeness" of the report; that is, to what extent it gives a valid picture of the scale of motion under study. Under the computational procedures used for evaluation and transmission of wind soundings it is quite possible for unrepresentative reports caused by small-scale 
oscillations to be included in the coded message. Various researchers have already been deeply concerned with this problem $[2,4]$.

The general accuracy of wind reports in the Tropics is no less than in middle latitudes, but as a rule greater precision and accuracy is desirable in tropical stations since relatively small variations in the wind vector are of greater importance and have a larger bearing on analysis and forecosting. Furthermore, due to sparsity of the staticns, decisions in analysis affecting very large areas are frequently based on just one report.

Some of the problems encountered in dealing with wind soundings, and how they can be solved by adoption of an averaging process, are illustrated in the example below, which is by no means extreme, but is adequate for the purpose. The winds for the levels from 2,000 to 10,000 $\mathrm{ft}$. received by teletypewriter for the stations Antigua, B.W.I. (861), San Juan, P.R. (526), and Sabana de la Mar, D.R. (467), on August 2, 1961, 0000 Gur, are listed below and appear in figure 1. The usual code has been retained, except for the $\mathrm{UZ}$ wind, which is transmitted to the nearest degree.

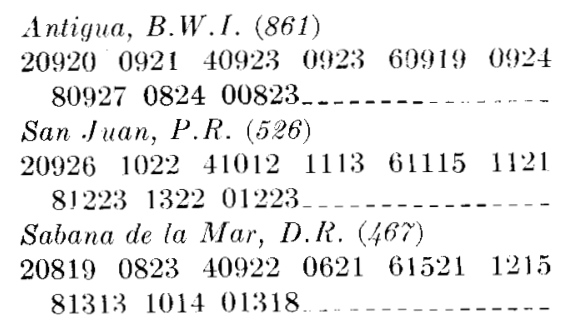

The sounding for Antigua illustrates an almost irleal case in which the flow is nearly constant throughout the layer. Only the speeds at 6,000 and $8,000 \mathrm{ft}$. deviate significantly from the rest of the reports. The report for any one of the levels, even $700 \mathrm{mb}$., would give a representative picture of the fow over the entire layer. If all stations behaved in the same fashion there wculd be little need for averaging and it would be necess: ry to : nilyze only one level (any one) between the surface and 10,000 $\mathrm{ft}$. in order to define the fow in this layer.

As a rule, conditions are not thet simple, is shown by the two stations a few hundred miles downstream. The wind sounding at sin Juan shows significant, but quite regular and steady, variations with altitude. There is a fairly strong flow from duc enst nea $r$ the surface, veering of the direction with height, with decrease of speeds in the levels 4,000 to $6,000 \mathrm{ft}$. and stronger fow above. In this case not all levels within the layer would give the same picture and if one wanted to obtain a representative wind for the layer as a whole an averaging would be desirable. In this example, however, reports near the conter of the lay deviate only slight ly from the menn.

The third example, for Sabana de la Mar, located about $200 \mathrm{mi}$. downstream from sian Juan, illustrates a very irregular distribution with height, a rather common type of sounding. Dif"erences in wind direction nnd speed within
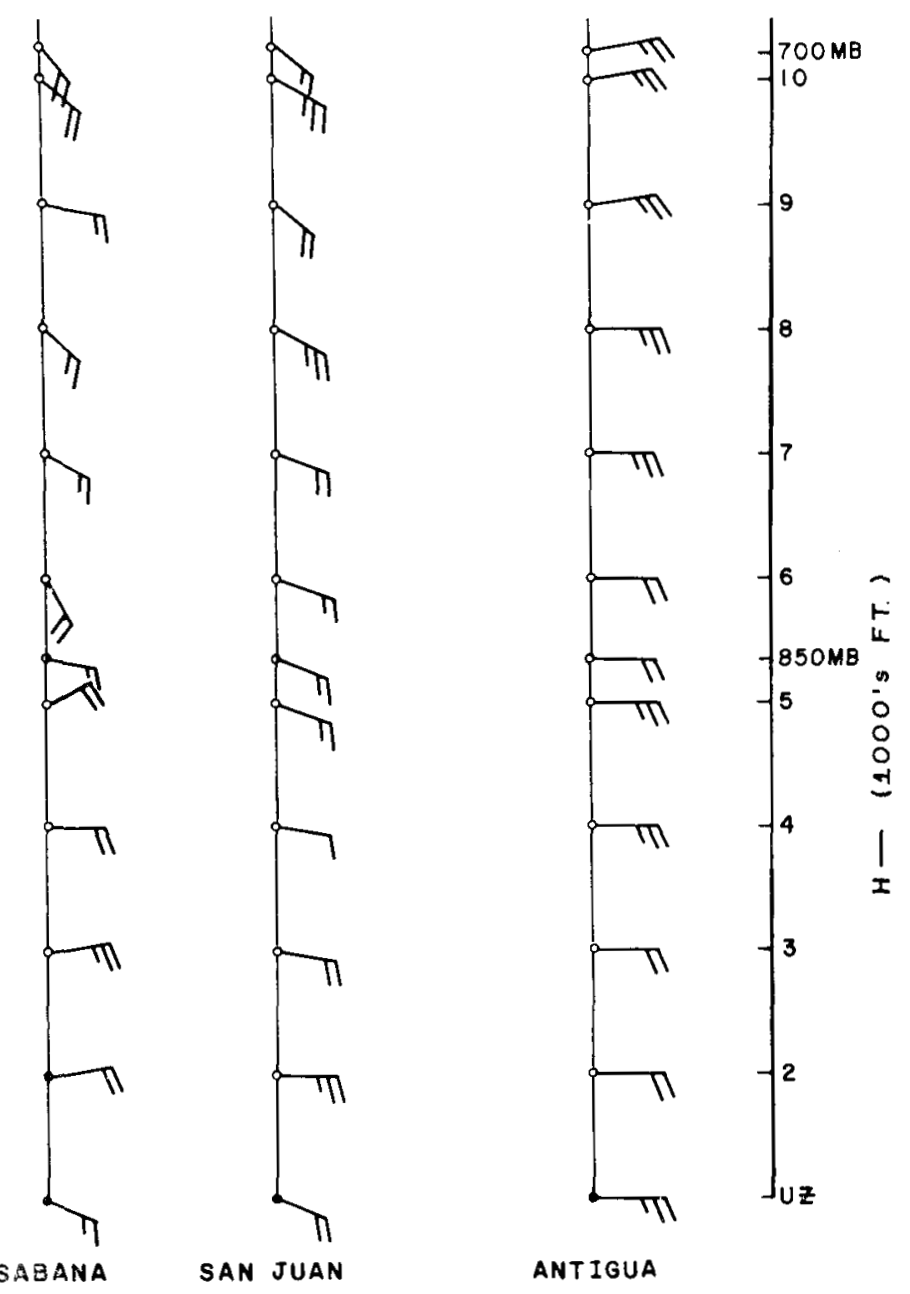

Ficiter 1.-Space section from Antigua, B. W. I. to Sabana de la Mar, I.R. Data for levels from 2,000 to $10,000 \mathrm{ft}$., August 2, 1961,0000 and. The letters UZ denote the mean wind for the laver from 3,000 to $10,000 \mathrm{ft}$.

a range of $90^{\circ}$ and $10 \mathrm{kt}$. are reported. One might suspeet the possibility of error in the reports at the $5,000-\mathrm{ft}$., $6,000-\mathrm{ft}$., and the $850-\mathrm{mb}$. levels. These particular reports were verified with the data published in the section on "Winds Aloft (hecked Data" of $[6]$ and found to be correct. Thus there were no errors in computation or transmission and the reported winds were evidently real, but probably due to unrepresentative small-scale oscillations. In this case, a menn wind is definitely superior; it is more representative of the entire layer and is one in which the analyst can place greater confidence.

As suggested more explicitly in figure 1 , il one were to go exclusively by the winds at the 5,000-ft. level, and no other information were available, a perturbation between San Juan and Sabana would be indicated. The winds at the 2,000 and 3,000-ft. levels also suggest a perturbation between those two stations, but the sounding at Sabana de la Mar as a whole is essentially characterized by ESE flow. The analysis of the low-level mean wind chart for that (lay (fig. 2) shows only one main perturbation in the 


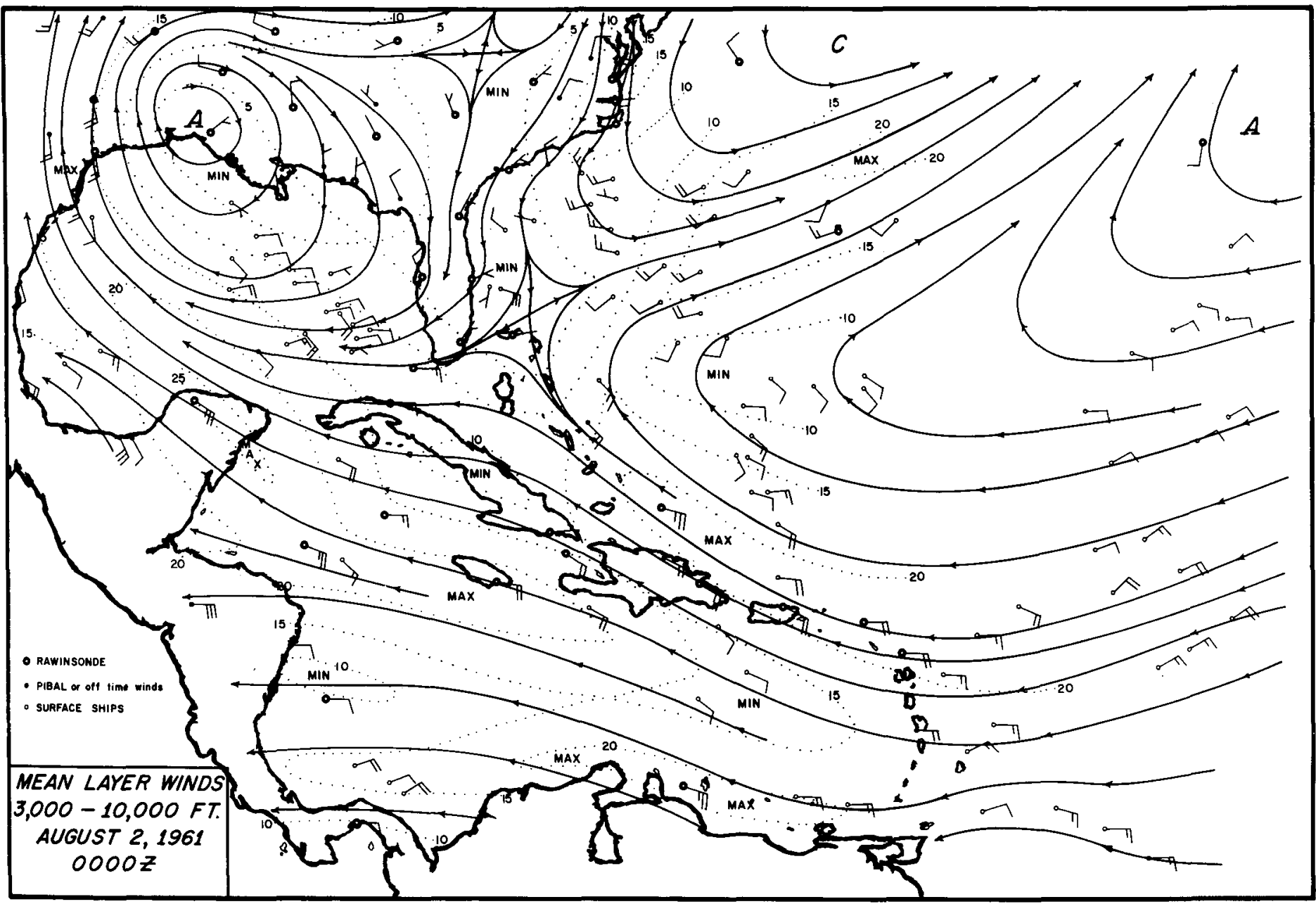

Figure 2, Mean-layer wind chart, 3,000 to $10,000 \mathrm{ft}$., August 2, 1961, 0000 amt. Isolachs (knots) in dotted lines.

trades located over central Cuba, with a trough connection to a cyclonic system in the westerlies farther north.

The examples discussed above were for stations in the trade winds belt, a regine of great constancy and steadiness. The averaging process would be even more advantageous in the upper levels and closer to the subtropical ridge, where winds are more variable in space and time.

The mean wind should also be less susceptible to evaluation errors than the conventional short-time wind. The longer time interval allows greater accuracy; the balloon generally has a longer displacement which can be measured with greater percentage accuracy. Finally, this procedure automatically smooths out short-period oscillations and features of shallow depth that are generally not representa tive of synoptic-scale motions. Similar conclusions were expressed by Allen [1] in reporting that extrapolation forecasts using integrated layer winds were somewhat more accurate than single-level forecasts. The desirability of computing mean winds on the plotting board at each station rather than by averaging individual winds is evident. In the latter procedure it is quite possible that unrealistic winds be included and have an undue influence on the computed mean. The problem of accuracy and representativeness of winds becomes more delicate when one is interested not only in determining the presence and position of synoptic features, but also in computing certain derived properties of the field of motion, such as the vorticity and divergence fields. Some of the difficulties caused by the sensitivity of computations on the wind field are discussed briefly below.

In the trade region the wind speed is normally from 10 to $20 \mathrm{kt}$. so that a fluctuation of only $2 \mathrm{kt}$. amounts to a 10 to 20 percent variation. On the other hand a difference in $10^{\circ}$ in the direction of a 12 -kt. wind corresponds to a vector difference of $2 \mathrm{kt}$., or about 16 percent. The effect of a given variation in winds on computations of vorticity and divergence can be illustrated with the computation cell shown in figure 3 , where wind reports are shown in a rectangular cell centered at point 0 , where a computation is to be made. These reports were taken from a chart analyzed for use in a numerical prediction experiment. In the grid designed for the experiment the size is slightly in excess of $100 \mathrm{~km}$., but for ease in computation the grid interval in figure 3 


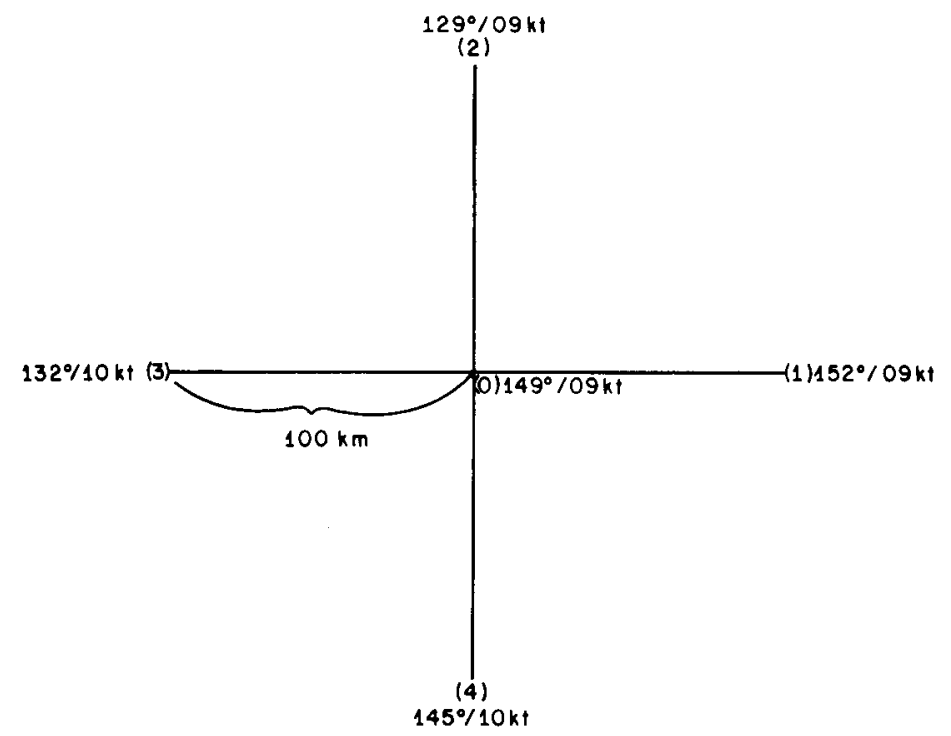

FiguRE 3.-Orthogonal grid cell for evaluation of vorticity and divergence.

has been taken as exactly $100 \mathrm{~km}$. The divergence $(D)$ and vorticity $(\xi)$ at point 0 (centered differences) are equal to:

$$
\begin{aligned}
& D=\frac{1}{2 h}\left(u_{1}-u_{3}+v_{2}-v_{4}\right) \\
& \zeta=\frac{1}{2 h}\left(v_{1}-v_{3}+u_{4}-u_{2}\right)
\end{aligned}
$$

The divergence and vorticity for the winds given in figure 3 are equal to (units of $10^{-6}$ sec. ${ }^{-1}$ ):

$$
\begin{aligned}
& D_{1}=1.8 \\
& \zeta_{1}{ }^{-}=6.5
\end{aligned}
$$

To test how a change in a given wind affects these computations, we consider arbitrary changes of $10^{\circ}$ in direction or of $2 \mathrm{kt}$. in speed, or both, in the wind at point 2 and then study the corresponding variation in vorticity and divergence. The following 5 cases give results for the given changes in the wind at point 2 :

Case 2. $W_{2}=119^{\circ} 09 \mathrm{kt}$. (wind backing of $10^{\circ}$, no change in speed)

$$
D_{2}=-1.5 \quad \zeta_{2}=9.0
$$

Case 3. $W_{2}=139^{\circ} 09 \mathrm{kt}$. (wind veering of $10^{\circ}$, no change in speed) $D_{3}=4.6 \quad \zeta_{3}=3.1$

Case $4 . W_{2}=129^{\circ} 11 \mathrm{kt}$. (no change in direction, increase of $2 \mathrm{kt}$. in speed)

$D_{2}=4.9 \quad \zeta_{2}=10.8$

Case 5. $W_{2}=119^{\circ} 11 \mathrm{kt}$. (backing of $10^{\circ}$, increase of $2 \mathrm{kt}$.) $D_{5}=0.8 \quad \zeta_{5}=13.6$

Case 6. $W_{2}=139^{\circ} 11 \mathrm{kt}$. (veering of $10^{\circ}$, increase of $2 \mathrm{kt}$.) $D_{6}=8.5 \quad \zeta_{6}=8.3$

Comparing each of these cases with the initial situation, $D_{1}$ and $\zeta_{1}$, we note in Case 2 that a variation in wind direction of $10^{\circ}$ changed the sign of the divergence and increased the vorticity by about 50 percent; in Case 3 a change in direction of $10^{\circ}$ in the opposite direction almost tripled the divergence and reduced the vorticity one-half; in Case 4 an increase in wind speed of $2 \mathrm{kt}$. (about 22 percent change) almost tripled the divergence and increased vorticity by more than 50 percent; in ( ase 5 a change of $10^{\circ}$ in direction and an increase in speed of $2 \mathrm{kt}$. combined to cut the divergence in half and double the vorticity; in Case 6 a change in direction of $10^{\circ}$ and increase in speed of $2 \mathrm{kt}$. combined to cause a five-fold increase in divergence and a slight increase in vorticity.

These results reveal nothing entirely new, for it is well known that computations of divergence and vorticity often involve small differences between large terms and errors may be large. Evidently, seemingly small variations in winds may result in more sizable variations in certain derived quantities. This may impose serious limitations on the success of numerical schemes in tropical analysis and forecasting. One may point out, though, that variations that may be introduced because of differences in analysis or inaccuracies in the winds at one station would affect not just one isolated point, but all points within a large area, so that the net effect may not be as large as in the computations illustrated above. There is, nevertheless, a requirement for the most precise and accurate definition of the wind field for computational work in the Tropics. There are some who believe that the inaccuracies introduced by rounding off to tens of degrees for coding purposes is enough to detract from the usefulness of wind reports. It is our belief that a large part of the difficulties discussed previously can be alleviated by the adoption of mean winds over welldefined and meaningful layers. The advantages of the mean wind would apply equally well if numerical objective techniques were used for analysis.

\section{COMPARISON BETWEEN THE UZ WINDS AND THE INDIVIDUAL REPORTS NEAR THE CENTER OF THE LAYER}

It has often been maintained that the difference between the wind near the center of a layer and the mean for the layer is not significant enough to justify the work expended in computing the mean. The factors of accuracy and representativeness, discussed previously, should by themselves justify the time spent in evaluation, but it might be of interest to investigate this difference. $A$ comparison was established between the mean winds for the lower, middle, and upper layers and the $850-\mathrm{mb}$., $500-\mathrm{mb}$., and $200-\mathrm{mb}$., winds, respectively, for a 1-month period (62 observations) at two stations (tables 1 and 2). The $850-\mathrm{mb}$. level is somewhat below the center of the 3,000 to $10,000-\mathrm{ft}$. layer, but this comparison has practical meaning because the $850-\mathrm{mb}$. level is often used to represent the low-level flow. One should keep in mind that in the usual winds reports direction is coded to the 
TABLE 1.-Frequencies in mean wind speed and in the difference between the direction and speed of the mean-layer wind and the wind at the standard millibar level near the center of the layer. Data for August 1961 at San Juan, P.R.

\begin{tabular}{|c|c|c|c|c|c|c|}
\hline & \multicolumn{2}{|c|}{ Low levels } & \multicolumn{2}{|c|}{ Middle levels } & \multicolumn{2}{|c|}{ Upper levels } \\
\hline & Freq. & $\%$ & Freq. & $\%$ & Freq. & $\%$ \\
\hline \multicolumn{7}{|l|}{ Mean speed $(k t)$ : } \\
\hline Under $5 . .$. & 0 & 0 & 7 & 11 & 2 & \\
\hline $6-10=\ldots \ldots$ & 4 & 6 & 16 & 26 & 7 & 12 \\
\hline $11-15 \ldots \ldots$ & $1 \overline{5}$ & 24 & 21 & 34 & 12 & 20 \\
\hline $16-20$ & 28 & 45 & 8 & 13 & 17 & 9 \\
\hline \multirow{2}{*}{\multicolumn{7}{|c|}{ Differences in wind direction of: }} \\
\hline & & & & & & \\
\hline $10^{\circ}$ or more & 18 & 29 & 31 & 51 & 15 & \\
\hline $15^{\circ}$ or mor & 6 & 10 & 20 & 33 & 5 & \\
\hline Differences in wind speed of $5 \mathrm{kt}$. or more. & 16 & 26 & 14 & 23 & 16 & 27 \\
\hline Difference in either $10^{\circ}$ or $5 \mathrm{kt}$. or more & 26 & 42 & 36 & 59 & 27 & 46 \\
\hline
\end{tabular}

nearest $10^{\circ}$, while the mean wind is transmitted to the nearest degree. The comparison in tables 1 and 2 treats the wind direction and speed separately; that is adequate for the purpose here. The frequency distribution of the speeds of the mean wind has been included to illustrate the strength of the flow.

At San Juan (table 1) the difference between the lowlevel mean wind and the $850-\mathrm{mb}$. wind was at least $10^{\circ}$ in direction and/or $5 \mathrm{kt}$. in speed about one-third of the time; at Sabana de la Mar (table 2) in about one-sixth of the observations. As expected, the deviations were larger and more frequent at the two upper levels. The degree of variations in the upper level at Sabana de la Mar was unexpectedly high; in fact, so large that one might suspect some bias in the observations. The deviations in general can not be ascribed to weak flow. In the trade current the mean speed was over $10 \mathrm{kt}$. in over 90 percent of the observations at both stations: at the upper level the winds were over $10 \mathrm{kt}$. in about 70 percent of the observations at Sabana de la Mar and in about 85 percent at San Juan. The comparison summarized in tables 1 and 2 was made again excluding the observations with speeds less than $10 \mathrm{kt}$., but the magnitudes of the percentages did not change appreciably.

These results indicate that the reports near the center of the layer differ from the mean to such an extent that they are not a good enough substitute for the mean. The differences for the most part are small but they have a considerable bearing on analysis and computations.

\section{SOME COMMENTS ON USES AND ANALYSIS OF MEAN WIND CHARTS}

The problems concerning data and analysis in the Tropics are at least equally serious in dealing with geopotential heights at isobaric levels. The limits of accuracy of height computations from radiosondes are large and contour analysis is even more frustrating than wind analysis. Computations of wind flow obtained from the geopotential field are also unreliable. Aside from the fact that the geostrophic approximation is not totally valid in low latitudes, the computations are very sensitive
TABLE 2.-Frequencies in mean wind speed and in the difference between the direction and speed of the mean-layer wind and the wind at the standard millibar level near the center of the layer. Data for August 1961 at Sabana de la Mar.

\begin{tabular}{|c|c|c|c|c|c|c|}
\hline & \multicolumn{2}{|c|}{ Low levels } & \multicolumn{2}{|c|}{ Middle levels } & \multicolumn{2}{|c|}{ Upper levels } \\
\hline & Freq. & $\%$ & Freq. & $\%$ & Freq. & $\%$ \\
\hline Mean speed (kt.): & & & & & & \\
\hline Under $5 \ldots$ & 0 & 0 & 3 & 5 & 4 & 6 \\
\hline $6-10=\cdots$ & 23 & 38 & $\begin{array}{l}19 \\
20\end{array}$ & $\begin{array}{l}31 \\
32\end{array}$ & $\begin{array}{l}14 \\
15\end{array}$ & $\begin{array}{l}23 \\
24\end{array}$ \\
\hline $16-20$ & 29 & 48 & 14 & 23 & 16 & 26 \\
\hline Over 20 & 4 & 7 & 6 & 10 & 13 & 21 \\
\hline Differences in wind direction of: & & & & & & \\
\hline $10^{\circ}$ or more. & 8 & 13 & 24 & 39 & 43 & 69 \\
\hline $15^{\circ}$ or more & 1 & 1 & 13 & 21 & 29 & 47 \\
\hline Differences in wind speed of $5 \mathrm{kt}$, or $\mathrm{m}$ & 3 & 5 & 10 & 16 & 32 & 52 \\
\hline Difference in either $10^{\circ}$ or $5 \mathrm{kt}$ & 10 & 16 & 29 & 47 & 55 & 89 \\
\hline
\end{tabular}

to small variations in the geopotential gradients. Thus, for most forecasting purposes, analysis of the wind field, for all its shortcomings, is preferred.

In most synoptic work being carried out at NHRP, preference is given to the mean-layer winds. One of the most notable applications has been in an experiment to test the barotropic model for a numerical forecast in the Caribbean area [5]. A series of 10 charts with 12-hr. continuity for the period September 14 to 19, 1960 was selected. The three mean-layer charts were analyzed independently and the fields of vorticity and divergence computed. The stream function field was computed from the vorticities and the barotropic numerical model applied to the stream function field.

The mean-layer winds computed over the Caribbean area are also being used in analysis work at Florida State University. $^{3}$ Other uses of mean winds of which we have knowledge, but over various other layers of the atmosphere, are in problems of fallout computations for Civil Defense operations, and in forecast operations in the Marshall Islands in $1958 .^{4}$

In the analysis of the mean-wind charts for the last two summer seasons, several points worth mentioning have come to light. As might be expected, the mean charts tend to average out minor perturbations that would show in some of the levels; only major systems are depicted in the mean charts. 'This has the disadvantage that some of the minor perturbations might still produce important weather variations at some stations. On the other hand, there is the advantage that it emphasizes the important perturbations that are more likely to develop into storm intensity.

Occasionally, systematic changes in regime occur within a layer, and interpretation of the mean wind is more difficult. For example, there are situations, sometimes encountered near the subtropical ridge, in which a shallow layer of easterlies is overlain by westerlies. The direction of the $3,000-10,000-\mathrm{ft}$. mean wind might be east

${ }^{3}$ Personal communication from Dr. N. E. LaSeur.

4 Personal communication from Mr. K. N. Nagler. 
or west, depending on the precise depth and strength of each regime. Similarly, an upper-level cyclone may extend its influence a varying distance downward from one day to the next, showing up as a perturbation, apparently of varying strength, in the easterlies of the mean-wind chart. Proper interpretation of such situations may require examination of data at individual levels.

In practice, the mean-wind charts showed great consistency from day to day. Systems which appeared on the charts for two successive davs generally were significant and could be followed for several more days. On the other hand, systems which appeared on the surlace rhart but not on the low-level mean-wind chart rarely proved important.

It has been the practice at NHRP to combine surface ship winds with the lower-layer mean wind at land stations as an aid in extending the analysis over oceanic areas. The ship data are usually composited over three 6-hourly map times centered on the time of the mean winds. Since surface and mean winds are obviously not identical it is necessary to consider the vertical shear if use of surface data is not to be misleading. 'This is done by studying soundings at land stations. The extent to which surface data are incorporated depends upon the judgment of the analyst; no objective method has been employed thus far. In regions or at times where little wind change with height is suspected, of ten the case in the trade wind regime, the analyst may add $5^{\circ}-15^{\circ}$ to the ship wind direction and 10-30 percent to the speed as a correction lor surface friction. On any given day, however, there are likely to be regions of significant vertical shear. For example, in figure 2 the surface winds off the Georgia coast were modified considerably, since the adjacent land stations report an appreciable increase of north and east wind components with height. Failure to do this would place a sharp trough on the coastline which would be at least partially fictitious. Thus, it cannot be emphasized too strongly that the mean-wind chart will not be useful if it becomes a surface chart at every coastline.

On the basis of the above remarks, the propriety of extending the mean-layer wind analysis far into the Atlantic may be questioned, since with increasing distance from a sounding the mean-wind chart inevitably tends toward a surface wind chart. The decision of where to stop the analysis depends very much on the objectives of the particular charts.

The mean winds over the layers defined in this report have been lound to be convenient for analysis in the Caribbean area. The same layers may not work equally well in other tropical areas. Even for the Caribbean, some other limits, covering a shallower or deeper layer, may work just as well.

\section{REFERENCES}

1. P. W. Allen, "Report on the Integrated Layer Wind Program," Bulletin of the American Meteorological Society, vol. 38, No. 7, Sept. 1957, p. 419 (abstract).

2. E. F. Danielsen, "The Laminar Structure of the Atmosphere and Its Relation to the Concept of a Tropopause," Archiv für Meteorologie, Geophysik und Bioklimatologie, Series A, Band 11, Heft 3, 1959, pp. 293-332.

3. I. K. Lilly and N. E. LaSeur, "A Statistical Summary of Some Caribbean Wind Data," Scientific Report No. 3, Florida State University, 1956, $31 \mathrm{pp}$.

4. H. Riehl, "Quantitative Representation of the Velocity Distribution Along the Vertical," Atmospheric Sciences Technical Report No. 14, Colorado State University, 1961, pp. 89-120.

5. S. L. Rosenthal, "The Current Status of Numerical Weather Prediction in the Tropics," Paper presented at the Joint American Meteorological Society-American Geophysical Union Meetings in Washington, April 25-28, 1962.

6. U.S. Weather Bureau, Daily Series, Synoptic Weather Maps Northern Hemisphere Sea Level and $500 \mathrm{mb}$. charts, Part II, Data Tabulations, August 1961. 